\title{
BMJ Open Quality A pilot volunteer reader programme decreases delirium days in critically ill, adult ICU patients
}

\author{
Sarah Jordan Reif (D) ," A Joseph Layon ${ }^{2,3}$
}

To cite: Reif SJ, Layon AJ. A pilot volunteer reader programme decreases delirium days in critically ill, adult ICU patients. BMJ Open Quality 2020;9:e000761. doi:10.1136/ bmjoq-2019-000761

Received 24 June 2019 Revised 30 May 2020 Accepted 19 June 2020

Check for updates

(c) Author(s) (or their employer(s)) 2020. Re-use permitted under CC BY-NC. No commercial re-use. See rights and permissions. Published by BMJ.

${ }^{1}$ Case Western Reserve University, Cleveland, Ohio, USA ${ }^{2}$ Department of Anesthesiology, University of Central Florida College of Medicine, Orlando, Florida, United States

${ }^{3}$ Professor of Anesthesiology, UniCamillus - International Medical University, Via di Sant'Alessandro, Rome, Italy

Correspondence to Ms. Sarah Jordan Reif; sjr117@case.edu

\section{INTRODUCTION}

Delirium, a form of acute brain dysfunction presenting as altered mental status, and impairment of memory, emotion, thinking, perception and behaviour ${ }^{1}$ develops over hours to days ${ }^{2}$ and is seen in $20 \%-80 \%^{13}$ of adult intensive care unit (ICU) patients, depending on the diagnostic method and severity of illness. Delirium diagnosis is often missed, as only $25 \%$ of patients experiencing this disorder are hyperactive. ${ }^{13}$ More prevalent is hypoactive delirium: patients appearing sedated, responding slowly to instructions or questions and, rarer still, mixed delirium patients may be hyperactive and hypoactive. ${ }^{3} 4$ There is also subsyndromal delirium, representing an intermediate state-not normal and yet not fully developed delirium. Delirium can lead to serious complications including increased length of ICU stay and increased readmission, institutionalisation and mortality rates. ${ }^{35}$ If not diagnosed or treated, delirium may lead to irreparable ${ }^{6}$ and delayed ${ }^{7-9}$ cognitive failure.

The risk factors for, and pathophysiology of, delirium are unclear. ${ }^{3} 10$ Social isolation is, however, a presumptive risk factor. We hypothesised that a programme of interaction-reading to critically ill ICU patients on a daily basis-might decrease delirium days. The data presented herein comprises our preliminary report.

\section{METHODS}

The ICU Reader Programme was born as a service project, using volunteers, in which we hoped to identify a decrease in delirium days-the 'signal'-that would prove our hypothesis. Readers were enrolled through the Volunteer Services Department, undergoing infection control and confidentiality training. The programme was composed of 11 Readers, mostly high school and college students, and ran from January 2017 to August 2017; patient data analysed for the study were collected between July and August 2017. The programme was designed and implemented by the authors (SJR, AJL) and principally managed by one of us (SJR). Hospital Volunteer Services had no available volunteers and advised us to recruit. Students were recruited due to their willingness to volunteer.

Each day, the volunteer asked the ICU Charge Nurse which patient they felt would be most suitable for reading and/or companionship. Readers would then ask the patientor surrogate if the patient was unable to interact-if they desired to be read to. When the answer was positive, the Reader would commonly spend 30-40 min reading and/or talking to two and three patients, individually, each day. We averaged 20-40 patients being read-to or talked-with weekly at the height of the programme. Books used included the Bible (Old and New Testaments), Koran, the local newspaper or one of several novels (eg, To Kill a Mockingbird or Sherlock Holmes detective novels). Some of the intubated and mechanically ventilated patients longed for more interaction, so notes were written on whiteboards or paper, and passed between the patient and Reader. Some patients desired only companionship.

Delirium was diagnosed using the 2014 updated version of the Confusion Assessment Method-ICU (CAM-ICU) scoring system, ${ }^{11-13}$ shown to tightly correlate with the Diagnostic and Statistical Manual-5 delirium diagnosis. CAM-ICU is a bedside scoring system that looks at altered levels of consciousness, inattention and disorganised thinking, at either acute or fluctuating levels. A patient is CAMICU positive if, either acutely or episodically, they meet the criteria for inattention and either altered level of consciousness or disorganised thinking. ${ }^{13}$ CAM-ICU scores, performed every 8 hours by bedside Registered Nurse, were compared 72 hours before and 72 hours after the reading episode; thus, patients served as their own controls. 
30

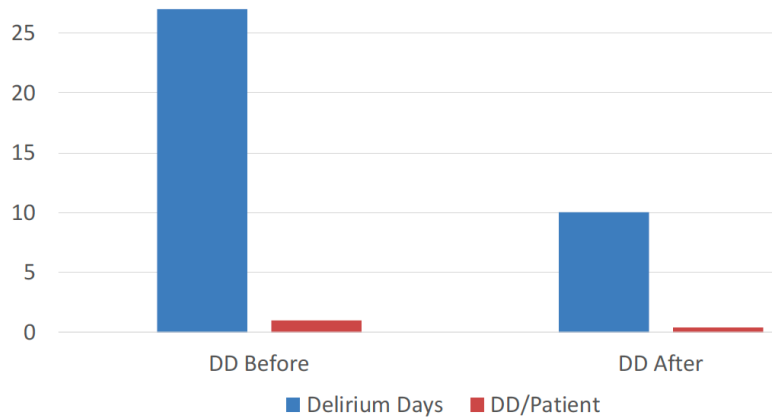

Figure 1 Delirium Days (DD) Before and After Reading Intervention.

Delirium days were used for the outcome of the entire population, before and after Reader intervention. A patient was positive for a delirium day if, during any one of the three daily evaluations, they met the CAM-ICU criteria for delirium.

Data were analysed for normality and, thereafter, parametric or non-parametric statistical methods were used. A $\mathrm{p}$ value of $<0.05$ was considered clinically and statistically significant.

\section{RESULTS}

Twelve of 33 patients we report on were diagnosed with delirium. Due to the small sample size, the data were not normally distributed. Thus, a non-parametric test (the Mann-Whitney test) was performed.

There were 27 total delirium days 72 hours before Reader intervention and 10 total delirium days 72 hours after Reader intervention. The number of delirium days per patient, respectively, were 0.82 (27/33 patients) versus $0.30(10 / 33$ patients) $(\mathrm{p}<0.05)$ (figure 1$)$. As the programme began as a service project, we were not able, for this preliminary communication, to account for other factors such as age, gender, days in the ICU, medications, comorbidities and so forth.

\section{DISCUSSION}

Delirium is known to increase not only costs of care but also duration of mechanical ventilation, length of stay, reintubation rate, long-term cognitive function, discharge to a long-term care facility and patient mortality. ${ }^{3514}$ Our ICU Reader Programme was a controlled, non-randomised study. The presence of a signal showing reduction of total delirium days in the cohort, as well as delirium days per patient, suggests that reading and talking with patients in the ICU may be an effective, simple and low-cost intervention.

As a service project, the ICU Reader Programme was well-designed and successfully implemented. As a research project, the programme was limited, having only collected data over a 1-month period. Due to unforeseen circumstances beyond our control, the programme was terminated and our access to data was limited to what is presented here. Nonetheless, there was a positive signal noted; clearly age, comorbidities and medications need to be taken into account in further studies.

ICU patients need to be maintained, as much as possible, with a normal sleep-wake cycle and with minimisation of social isolation to avoid the onset of delirium; this also could maintain their safety, comfort and overall physical and psychological function.

The ICU Reader Programme was a pilot project, and the signal we have noted must be taken as preliminary. A randomised, controlled and multicentre study is warranted, as the potential for bias is real. The number of patients studied is small, and individuals considered 'appropriate' for interaction with our Readers were chosen by the ICU charge nurse; both these issues may have inadvertently introduced bias. It will require further study and analysis to determine if the material read matters as much, or more, than the act of reading itself. This is of particular importance in the era of severe acute respiratory syndrome coronavirus 2 when, for patients considered 'person under investigation' (patients with symptoms but no confirmed diagnosis), isolation is the norm and the risk of delirium is significant.

\section{CONCLUSION}

An ICU Reader Programme appears to decrease risk for, and duration of, delirium in adult ICU patients. Whether this effect is related to the reading itself or simple companionship, as well as the impact of comorbidities, age, gender and medications, is unclear.

Twitter A Joseph Layon @ajlayon

Acknowledgements We thank the ICU Reader Programme volunteer readers and the nurses of the Geisinger Medical Centre Adult ICU.

Contributors SJR and AJL designed and carried out the ICU Reader Project. SJR organised the volunteers and managed the programme. AJL compiled and analysed the data, and drafted the initial version of the paper. SJR and AJL revised the paper and are responsible for the overall content.

Funding The authors have not declared a specific grant for this research from any funding agency in the public, commercial or not-for-profit sectors.

Competing interests None declared.

Patient and public involvement Patients and/or the public were not involved in the design, conduct, reporting or dissemination plans of this research.

Patient consent for publication Not required.

Provenance and peer review Not commissioned; externally peer reviewed. Data availability statement All data relevant to the study are included in the article.

Open access This is an open access article distributed in accordance with the Creative Commons Attribution Non Commercial (CC BY-NC 4.0) license, which permits others to distribute, remix, adapt, build upon this work non-commercially, and license their derivative works on different terms, provided the original work is properly cited, appropriate credit is given, any changes made indicated, and the use is non-commercial. See: http://creativecommons.org/licenses/by-nc/4.0/.

ORCID iD

Sarah Jordan Reif http://orcid.org/0000-0002-7451-8289 


\section{REFERENCES}

1 Marcantonio ER. Delirium in hospitalized older adults. N Engl J Med 2017;377:1456-66.

2 Meagher DJ, Morandi A, Inouye SK, et al. Concordance between DSM-IV and DSM-5 criteria for delirium diagnosis in a pooled database of 768 prospectively evaluated patients using the delirium rating scale-revised-98. BMC Med 2014;12:164-73.

3 Girard TD, Pandharipande PP, Ely EW. Delirium in the intensive are unit - a review. critical care 2008;12:S3.

4 Burns A, Gallagley A, Byrne J. Delirium. J Neurol Neurosurg Psych 2004;75:362-7.

5 Ouimet S, Riker R, Bergeron N, et al. Subsyndromal delirium in the ICU: evidence for a disease spectrum. Intensive Care Med 2007;33:1007-13.

6 Wan M, Chase JM. Delirium in older adults: diagnosis, prevention, and treatment. Br Columbia Med J 2017;59:165-70.

7 Ely EW, Gautam S, Margolin R, et al. The impact of delirium in the intensive care unit on hospital length of stay. Intensive Care Med 1900;2001:1892.
8 Ely EW, Shintani A, Truman B, et al. Delirium as a predictor of mortality in mechanically ventilated patients in the intensive care unit. JAMA 2004;291:1753-62.

9 Jackson JC, Gordon SM, Hart RP, et al. The association between delirium and cognitive decline: a review of the empirical literature. Neuropsychol Rev 2004;14:87-98.

10 Fong TG, Tulebaev SR, Inouye SK. Delirium in elderly adults: diagnosis, prevention and treatment. Nat Rev Neurol 2009;5:210-20.

11 Bergeron N, Skrobik Y, Dubois M-J. Delirium in critically ill patients (commentary). Critical Care 2002;6:181-2.

12 Chanques G, Ely EW, Garnier O, et al. The 2014 updated version of the Confusion Assessment Method for the Intensive Care Unit compared to the $5^{\text {th }}$ version of the Diagnostic and Statistical Manual of Mental Disorders and other current methods used by intensivists. Ann Intensive Care 2018;8:33-42.

13 Ely EW. Confusion assessment method for the ICU (CAM-ICU). The complete training manual, 2014. Available: http://www.icudelirium. org/docs/CAM ICU training.pdf [Accessed 6 Sep 2018].

14 Oh ES, Fong TG, Hshieh TT, et al. Delirium in older persons: advances in diagnosis and treatment. JAMA 2017;318:1161-74. 